\title{
The geoaccumulation index and enrichment factor of mercury in mangrove sediment of Port Klang, Selangor, Malaysia.
}

\begin{abstract}
Mangrove areas are important to the ecosystem. One of its crucial functions is as a sink of pollutants, especially metal ions. However, the accumulation of metals in mangrove sediment can generate negative impacts on plant growth, microbial activity, and soil fertility. Apart from that, the severity of the impact is highly influenced by the type of metal found in the sediment and the quality of sediment itself. One of the metals that have adverse effects on the environment is mercury. The objectives of this study are to determine the concentration and distribution of mercury and to assess the enrichment of mercury in Port Klang mangrove sediment by using geoaccumulation index and enrichment factor. Sediment samples were collected from 30 sampling points that cover Langat River and Klang River estuaries, Lumut Straits, Pulau Klang, and Pulau Indah. During sampling, water parameters such as $\mathrm{pH}$, salinity, electrical conductivity, and total dissolved solids were measured in situ, whereas the total mercury in sediment samples was determined at the laboratory using inductively coupled plasma mass spectrometry. In this study, mercury was found to be concentrated along Lumut Strait especially in the mixing zone near the confluence of Langat River and at the jetty to Pulau Ketam. The geoaccumulation index and enrichment factor (calculated using logarithmized data of the reference element) found that three stations were enriched with mercury. In addition, geoaccumulation index was also observed to be more objective compared to enrichment factor whose results were influenced by the concentration of reference element used.
\end{abstract}

Keyword: Mercury; Mangrove sediment; Enrichment factor; Geoaccumulation index. 